\title{
Detection and molecular characterization of enteric viruses in enteritis-affected commercial broiler chickens in India
}

\author{
B. KAITHAL ${ }^{1}$, N. JINDAL ${ }^{* *}$, P. KUMAR², S. K. MOR ${ }^{3}$
}

\begin{abstract}
${ }^{1}$ Department of Veterinary Public Health and Epidemiology, and ${ }^{2}$ Department of Animal Biotechnology, College of Veterinary Sciences, Lala Lajpat Rai University of Veterinary and Animal Sciences, Hisar - 125 004, India; ${ }^{3}$ Department of Veterinary Population Medicine and Veterinary Diagnostic Laboratory, College of Veterinary Medicine, University of Minnesota, 1333 Gortner Ave, St. Paul, MN 55108, USA
\end{abstract}

Received September 28, 2015; revised March 1, 2016; accepted October 17, 2016

\begin{abstract}
Summary. - A study was conducted to detect and characterize the enteric viruses (chicken astrovirus, avian nephritis virus and avian orthoreovirus) present in flocks of commercial broiler chickens suffering from enteritis in Haryana, India. The intestinal contents were collected from 65 enteritis-affected flocks (cases) and tested by reverse transcription PCR (RT-PCR). Of these 65 cases, 35 (53.80\%) were positive for a single virus and $26(40.00 \%)$ for two viruses. The remaining four samples were negative for all three viruses tested. Of the 65 cases, 57 were positive for chicken astrovirus (CAstV) while 30 cases had avian nephritis virus (ANV). None of the cases were positive for orthoreovirus. Comparison of $12 \mathrm{CAstVs}$ of this study with previously published CAstV sequences revealed nucleotide identities ranging from 73.20 to $98.00 \%$. The nucleotide identities ranged between 83.10-95.50\% when nine ANVs of this study were compared with previously reported ANV sequences. The amino acid sequences of CAstVs in comparison to previously published sequences revealed certain unique changes. Phylogeny based on polymerase gene revealed that CAstVs and ANVs of this study were under the same monophyletic clade. In conclusion, a large number of broiler chicken flocks experiencing enteritis were positive for CAstV and ANV by RT-PCR. The presence of more than one enteric virus in enteritis-affected flocks and changes at the genetic level in these viruses may affect the severity of disease.
\end{abstract}

Keywords: chicken astrovirus; avian nephritis virus; avian orthoreovirus; broiler chicken; India

\section{Introduction}

Several enteric diseases have been described in chickens over the years namely, coronaviral enteritis, maldigestion syndrome, malabsorption syndrome, runting and stunting syndrome (RSS) and viral enteritis. Enteritis is an economically important disease of young chickens and is characterized by diarrhoea, poor weight gain, and in some flocks, high

"Corresponding author. E-mail: nareshjindal1@gmail.com; phone: +91-1662-289323.

Abbreviations: ANV = avian nephritis virus; ARV = avian reovirus; $\mathrm{CAstV}=$ chicken astrovirus; $\mathrm{GI}=$ gastrointestinal; $\mathrm{PES}=$ poult enteritis syndrome; RSS = runting and stunting syndrome; RT$\mathrm{PCR}=$ reverse transcription $\mathrm{PCR}$ mortality (Saif, 2003). Enteric viruses can cause damage to the gastro-intestinal (GI) tract of birds thereby providing a conducive environment for bacteria and/or protozoa to grow and cause further damage to the gut. It is possible that damage caused to the gut initially by enteric viruses and subsequently by secondary pathogens may lead to irreversible changes to the host, which may result in irreversible damage to the flock (Saif, 2003). Several pathogens such as avian rotavirus, astrovirus, reovirus, coronavirus, adenovirus, Salmonella, Escherichia coli, Enterococcus, and Eimeria spp. have been detected either alone or in different combinations from broiler chickens and turkey flocks afflicted with enteritis (Barnes et al., 2000; Jindal et al., 2010; Pantin-Jackwood et al., 2007, 2008, 2011; Day and Zsak, 2013; Koo et al., 2013; Mettifogo et al., 2014).

Astroviruses are small, non-enveloped, single-stranded, positive-sense RNA viruses belonging to the family Astro- 
viridae (Matsui and Greenberg, 2001), which is divided into two genera: Mamastrovirus containing mammalian astroviruses and Avastrovirus containing avian astroviruses. To date, two different astrovirus species have been recognized in chickens: avian nephritis virus (ANV) and chicken astrovirus (CAstV). The ANV, originally regarded as a picornavirus, was characterized as the first astrovirus of chickens on the basis of its genome sequence (Imada et al., 2000) and was first isolated from the cloacal contents of apparently normal broiler chickens (Yamaguchi et al., 1979). This virus is known to cause diarrhoea, tubulenephrosis, interstitial nephritis, gout and death in broiler chickens (Mandoki et al., 2006b; Bulbule et al., 2013). Serological studies suggested widespread prevalence of ANV infections in commercial broiler chickens in various countries (Imada et al., 1980; Connor et al., 1987). In recent years, ANVs have been detected in enteritis- or RSS-affected broiler chickens from many different countries by molecular methods (Pantin-Jackwood et al., 2008; Smyth et al., 2009; Roussan et al., 2012; Koo et al., 2013; Mettifogo et al., 2014).

The CAstVs are antigenically and serologically distinct from ANVs, although their genomes share some sequence identity with ANV and other astroviruses (Koci and Schultz-Cherry, 2002). The detection/isolation of CAstVs has been reported from broiler chickens exhibiting RSS and from dead-in-shell chicks having hatchability problems (Baxendale and Mebatsion, 2004; Smyth et al., 2009; Pantin-Jackwood et al., 2011; Kang et al., 2012; Koo et al., 2013; Smyth et al., 2013; Mettifogo et al., 2014; SajewiczKrukowska et al., 2016). In most of these studies, CAstVs have been detected using reverse transcription PCR (RTPCR) and/or quantitative RT-PCR targeting ORF1b or ORF2 genes.

Avian reoviruses (ARVs) (the genus Orthoreovirus, the family Reoviridae) are prevalent worldwide and are often associated with stunting syndrome, malabsorption syndrome, tenosynovitis, respiratory disease, immunosuppression, and enteric disease in chickens, turkeys and other avian species (Rosenberger, 2003). The ARVs have been detected in enteritis- or RSS-affected broiler chickens (Davis et al., 2013; Koo et al., 2013; Mettifogo et al., 2014).

In India, Bulbule et al. (2013) published a study on the detection of CAstVs in gout-affected broiler chickens. However, there seems to be no published report on detection and characterization of CAstVs, ANVs and ARVs from enteritis-affected broiler chickens. We conducted this study for the detection and characterization of three enteric viruses (CAstV, ANV and ARV) in enteritis-affected broiler chickens in India. The aim was to detect the presence of these enteric viruses and to elucidate the genomic diversity among circulating strains of these three viruses in broiler chickens experiencing enteritis.

\section{Materials and Methods}

Collection of samples. Birds are routinely submitted to the Disease Investigation Laboratory of the Department of Veterinary Public Health and Epidemiology, College of Veterinary and Animal Sciences, Lala Lajpat Rai University of Veterinary and Animal Sciences, Hisar, Haryana (India) for disease investigation. During years 2011 to 2015, intestinal contents were collected from 65 enteritis-affected broiler chicken flocks. A flock (case) was diagnosed as suffering from enteritis based on clinical findings of diarrhoea, dullness and depression and/or post-mortem findings of thin-walled intestines with watery, foamy and frothy intestinal contents. The intestinal contents of 4-5 chicks were pooled to make one pooled sample. Thus a total of 65 pooled samples of intestinal contents (representing 65 flocks) were collected and processed further. Pooled samples were referred hereinafter as 'sample'. A $10 \%$ suspension of the samples was prepared in phosphate buffered saline (PBS; $\mathrm{pH}$ 7.4) followed by homogenization and centrifugation at 3,000 rpm for $10 \mathrm{~min}$ at room temperature. The supernatants were collected and tested for the presence of CAstV, ANV and ARV by RT-PCR.

$R N A$ extraction and RT-PCR. Total genomic RNA was extracted from the supernatant using Trizol LS reagent (Invitrogen, USA) following the manufacturer's protocol. The extracted RNA was dissolved in $40 \mu \mathrm{l}$ of nuclease free water and was stored at $-20^{\circ} \mathrm{C}$ until used. Total RNA extracted from known strains of ARV, $\mathrm{CAstV}$ and $\mathrm{ANV}$ was used as positive control. The extracted RNA templates were subjected to RT-PCR individually for CAstV, ANV and ARV using virus-specific primers. Primers for polymerase gene of CAstV (F-5'-GAYCARCGAATGCGRAGRTTG-3' and R-5'-TCAGTGGAAGTGGGKARTCTA-3') with a product size of 362 bp; polymerase gene of ANV (F-5'-GYTGGGC GCYTCYTTTGAYAC-3' and R-5'-CRTTTGCCCKRTARTCT TTRT-3') with a product size of 473 bp (Day et al., 2007); and S4 gene of ARV (F-5'-GTGCGTGTTGGAGTTTCCCG-3' and R-5'-TACGCCATCCTAGCTGGA-3') with an expected product size of 1120 bp (Pantin-Jackwood et al., 2008) were used. Amplification for all three viruses was carried out using OneStep RT-PCR kit (Qiagen, USA). The reaction mix for all three viruses consisted of 1x RT-PCR reaction buffer, $320 \mu \mathrm{mol} / \mathrm{l}$ of each deoxynucleotide triphosphate (dNTP), $0.6 \mu \mathrm{mol} / \mathrm{l}$ of each primer, $2 \mu \mathrm{l}$ of enzyme blend and $1.5 \mu$ of extracted RNA for a total volume of $25 \mu$ l. The reaction conditions for $\mathrm{CAstV}$ consisted of reverse transcription at $50^{\circ} \mathrm{C}$ for $30 \mathrm{~min}, \mathrm{Taq}$ activation at $94^{\circ} \mathrm{C}$ for $15 \mathrm{~min}, 35$ cycles of denaturation at $94^{\circ} \mathrm{C}$ for $30 \mathrm{sec}$, annealing at $53^{\circ} \mathrm{C}$ for $1 \mathrm{~min}$, extension at $72^{\circ} \mathrm{C}$ for $1 \mathrm{~min}$, and a final extension at $72^{\circ} \mathrm{C}$ for $10 \mathrm{~min}$. The reaction conditions for ANV and ARV were similar to those of CAstV except that the annealing temperatures for ANV and ARV were $56^{\circ} \mathrm{C}$ and $57^{\circ} \mathrm{C}$, respectively. The amplified PCR products were visualized on $1.2 \%$ agarose gel in Tris-acetate ethylenediamine tetraacetic acid buffer. In positive cases, bands of 1120, 362 and 473 bp were observed for ARV, CAstV and ANV, respectively. Jindal et al. (2012) tested fivefold serial dilutions of the ARV and this virus in a multiplex RT-PCR assay could be detected up to the last 
dilution (1:625) which corresponded to total RNA concentration of $27 \mathrm{ng} / \mu \mathrm{l}$ of ARV.

Sequencing and phylogenetic analysis. Randomly selected viruspositive PCR products (12 CAstVs and nine ANVs) were purified using a QIAquick PCR purification kit (Qiagen). The purified PCR products were subjected to sequencing in both directions using the same primers as used for virus amplification. Since none of the samples were positive for ARV by RT-PCR, no sequencing was done for this virus. The sequencing was done in the Department of Animal Biotechnology using an ABI 3130XL sequencer. A contig sequence was generated from forward and reverse sequence using DNA Baser software program. The contig sequences were subjected to BLAST analysis (http://www.ncbi.nlm.nih.gov) to confirm their identity. The related sequences obtained during BLAST search were retrieved from
GenBank and multiple sequence alignment was carried along with nucleotide (nt) sequences of present study using Clustal W program of MEGA 6.0 software (Tamura et al., 2013). The pair wise distance method using the maximum composite likelihood model was used for computing evolutionary distances. A phylogenetic tree of aligned sequences of each virus was then constructed by Neighbor-Joining method with 500 bootstrap values. A conservation plot was constructed using Bioedit software program to determine variations at the nt level among different strains of the present study and earlier reported viral strains of India and abroad. Further, the nt sequences were translated to deduced amino acid (aa) sequences, which were also compared using conservation plot to determine differences at the aa level, if any. The details of previously published sequences used for comparison are given in Table 1.

Table 1. Previously published polymerase gene sequences of astrovirus and avian nephritis virus used for comparison

\begin{tabular}{|c|c|c|c|c|}
\hline Gene/Virus & Strain name & Country & $\begin{array}{l}\text { GenBank } \\
\text { Acc. No. }\end{array}$ & Host species \\
\hline \multirow{34}{*}{$\begin{array}{l}\text { Polymerase gene of } \\
\text { chicken astrovirus }\end{array}$} & GA2011/2007 & USA & JF414802 & Chicken \\
\hline & GA-SEP-A450-05/2005 & USA & DQ324844 & Chicken \\
\hline & DE-SEP-A654-05/2005 & USA & DQ324848 & Chicken \\
\hline & GE-SEP-A364-05/2005 & USA & DQ324839 & Chicken \\
\hline & GE-SEP-A792-05/2005 & USA & DQ324849 & Chicken \\
\hline & GE-SEP-A368-05/2005 & USA & DQ324842 & Chicken \\
\hline & $4175 / 2006$ & USA & JF832365 & Chicken \\
\hline & MO-SEP-A799/2005 & USA & DQ324850 & Chicken \\
\hline & ADL121238/2012 & S. Korea & KC593413 & Chicken \\
\hline & ADL110638/2011 & S. Korea & KC593405 & Chicken \\
\hline & ADL102655-1/2010 & S. Korea & JN635502 & Chicken \\
\hline & ADL122057/2012 & S. Korea & KC593414 & Chicken \\
\hline & 324595_08/2008 & Italy & JN048391 & Chicken \\
\hline & 325004_08/2008 & Italy & JN048401 & Chicken \\
\hline & 327845-1_08/2008 & Italy & JN048402 & Chicken \\
\hline & $324996-4 / 2008$ & Italy & JN048400 & Chicken \\
\hline & $324169 / 2008$ & Italy & JN048393 & Chicken \\
\hline & $11672 / 2004$ & UK & EU668998 & Chicken \\
\hline & CRO-443/2011 & Croatia & JQ946070 & Duck \\
\hline & Indovax/APF/1319/2013 & India & KC865608 & Chicken \\
\hline & Indovax/EI/1078/2013 & India & KC855215 & Chicken \\
\hline & Indovax/SH/1079/2013 & India & KC855214 & Chicken \\
\hline & PDRC/1803/South zone/2012 & India & KC633179 & Chicken \\
\hline & PDRC/1804/South zone/2012 & India & KC633180 & Chicken \\
\hline & PDRC/200/East zone/2011 & India & JX945868 & Chicken \\
\hline & PDRC/447/South zone/2012 & India & KC633178 & Chicken \\
\hline & PDRC/579/West zone/2011 & India & JX945879 & Chicken \\
\hline & PDRC/580/West zone/2011 & India & JX945880 & Chicken \\
\hline & PDRC/588/North zone/2011 & India & JX945881 & Chicken \\
\hline & PDRC/589/North zone/2011 & India & JX945882 & Chicken \\
\hline & USP238-1/2010 & Brazil & JF309118 & Chicken \\
\hline & USP337-2/2009 & Brazil & GU585496 & Chicken \\
\hline & USP388-3/2010 & Brazil & JF309117 & Chicken \\
\hline & USP358-4/2009 & Brazil & GU014472 & Chicken \\
\hline
\end{tabular}




\begin{tabular}{|c|c|c|c|c|}
\hline Gene/Virus & Strain name & Country & $\begin{array}{l}\text { GenBank } \\
\text { Acc. No. }\end{array}$ & Host species \\
\hline \multirow{26}{*}{$\begin{array}{l}\text { Polymerase gene of } \\
\text { avian nephritis virus }\end{array}$} & 2009/Sichuan & China & НM029238 & Chicken \\
\hline & $255554-3 / 2009$ & Italy & JN048380 & Guinea fowl \\
\hline & ADL110638/2011 & S. Korea & KC593390 & Chicken \\
\hline & ADL111234/2011 & S. Korea & KC593391 & Chicken \\
\hline & ADL120886/2012 & S. Korea & KC593400 & Chicken \\
\hline & ADL120915/2012 & S. Korea & KC593401 & Chicken \\
\hline & CRO-799/2011 & Croatia & JQ692619 & Chicken \\
\hline & DE-CK-SEP/811-2005 & USA & HQ188693 & Chicken \\
\hline & G4260/1999 & Japan & AB033998 & Chicken \\
\hline & GA/SEPA368/05/2010 & Australia & HM017850 & Chicken \\
\hline & GA-CK-SEP/364-2005 & USA & HQ188698 & Chicken \\
\hline & GA-CK-SEP/451-2005 & USA & HQ188696 & Chicken \\
\hline & GA-CK-SEP/458-2005 & USA & HQ188699 & Chicken \\
\hline & NC-TK-SEP/537-2005 & USA & HQ188695 & Turkey \\
\hline & NC-TK-SEP/670-2005 & USA & HQ188697 & Turkey \\
\hline & NSW3/2010 & Australia & HМ017854 & Chicken \\
\hline & NSW4/2010 & Australia & HM017855 & Chicken \\
\hline & Sichuan80/2011 & China & HQ603055 & Chicken \\
\hline & Sichuan87/2011 & China & HQ603056 & Chicken \\
\hline & TK/G145/08/2008 & Poland & HQ317722 & Turkey \\
\hline & $\mathrm{VIC} 3 \mathrm{~b} / 2010$ & Australia & KM985697 & Chicken \\
\hline & VIC-5b/2010 & Australia & KM985700 & Chicken \\
\hline & VIC-6a/2010 & Australia & KM985702 & Chicken \\
\hline & NSW 1a & Australia & KM985690 & Chicken \\
\hline & VIC-5c/2010 & Australia & KM985701 & Chicken \\
\hline & VIC-4a/2010 & Australia & KM985694 & Chicken \\
\hline
\end{tabular}

GenBank accession numbers. The sequence data of the present study were submitted to the GenBank database with the following accession numbers (Acc. Nos.): CAstV polymerase gene (KT386327 to KT386338) and ANV polymerase gene (KT376411 to KT376419).

\section{Results}

\section{Prevalence of enteric viruses}

Of the samples collected from 65 enteritis-affected cases, 61 (93.80\%) were positive for either CAstV or ANV or both and four samples did not contain any of the three viruses tested. Also, none of the 65 samples was positive for ARV. A total of 57 samples (87.69\%) were positive for CAst $\mathrm{V}$ while 30 samples (46.15\%) were positive for ANV by RT-PCR (Table 2). Of the total samples, 35 (53.80\%) were positive for individual viruses and $26(40.00 \%)$ for both CAstV and ANV (Table 2).

\section{Nucleotide and amino acid identities}

The PCR products from $12 \mathrm{CAstV}$-positive samples were purified and sequenced and compared with previously pub-
Table 2. Detection of enteric viruses alone or in combination

\begin{tabular}{lc}
\hline Pathogen(s) & $\begin{array}{c}\text { Number (\%) of intestinal content samples posi- } \\
\text { tive for indicated viruses }\end{array}$ \\
\hline CAstV & $31(47.69)$ \\
ANV & $4(6.15)$ \\
ARV & 0 \\
CAstV + ANV & $26(40.00)$ \\
CAstV + ARV & 0 \\
ANV + ARV & 0 \\
Total & $61(93.84)$ \\
\hline
\end{tabular}

${ }^{a}$ A total of 65 samples were examined. Four samples were negative for all three viruses. Total samples positive for CAstV $=57(31+26)$ and for $\mathrm{ANV}=30(4+26), \mathrm{CAstV}=$ chicken astrovirus; $\mathrm{ANV}=$ avian nephritis virus; $\mathrm{ARV}=$ avian reovirus.

lished polymerase gene sequences. The polymerase gene nt sequences of CAstV (corresponding to nt positions 4170 to 4494 of GenBank Acc. No. JF414802) were used to compare the nt identities with previously published CAstV strains from India and abroad. Nucleotide sequence similarity of 85.90 to $100 \%$ was observed among different strains of this study. 
Comparison of CAstVs of this study with those of chicken origin $\mathrm{CAstV}$ from India revealed nt identities ranging between $86.80-98.00 \%$. Similarly, when CAstV sequences of this study were compared with CAstVs from abroad, the identities ranged from 73.20 to $97.60 \%$. The comparison of deduced aa sequences of CAstVs of the present study corresponding to a positions $248-348$ of ORF1b of protein ID AEE88304 revealed that the CAstVs of this study had 91.00-100\% identity among themselves. At the aa level, our CAstV strains had identity of $91.00-100 \%$ with CAstV strains from India and of 82.10-98.50\% with those from other countries.

The polymerase gene nt sequences of ANV of this study (corresponding to nt positions 3722-4083 of GenBank Acc. No. HM029238) were used to compare the nt identities with previously published ANV strains from abroad. Comparison of ANV sequences among themselves revealed nt identity of 87.60-98.90\%. Comparison of ANVs of this study with ANV sequences of chicken origin from abroad revealed nt identities ranged from $83.10-95.50 \%$. Similarly, when ANV sequences of this study were compared with sequences of turkey and guinea fowl astroviruses, the identities ranged from $84.80-88.30 \%$ and $86.00-89.90 \%$, respectively. The analysis of deduced aa sequences of ANV corresponding to aa positions 1238-1356 of ORF1b of protein ID ADG45752 revealed that the ANV strains of this study had 91.50 to $100 \%$ identity among themselves and 89.80 to $100 \%$ identity with ANV strains of non-Indian origin. Compared to three turkey astrovirus strains used for comparison, the identity at the aa level was 93.20 to $96.60 \%$.

The polymerase gene nt sequences of CAstV (corresponding to nucleotide positions 4170 to 4494 of GenBank Acc. No. JF414802) were translated to deduced aa sequences. The aa sequences of CAstV of this study corresponding to aa positions from 248348 of ORF1b of protein ID AEE88304 revealed certain changes as depicted in Table 3. Nine of the $12 \mathrm{CAstV}$ strains of this study revealed a change of aa from isoleucine to valine at position 256. Similarly, eight of the 12 strains also revealed aa change from lysine to aspartic acid at position 257 when compared to the reference strain. The strains that showed aa change at position 257 also showed aa change at position 256. None of these changes (i.e. isoleucine to valine at position 256 and lysine to aspartic acid at position 257) were observed in CAstV strains used for comparison. Similarly, the change of aa from leucine to glutamic acid in three CAstVs of this study at position 310 was unique as this change was not observed in any of the CAst $\mathrm{V}$ strains used for comparison. The change of aa from serine to phenylalanine and glycine to cysteine at positions 330 and 331 in three and two CAstV strains of this study, respectively were also unique. Point mutations at one or two positions in one or two CAstVs of this study were also observed (Table 3 ).

The polymerase gene nt sequences of ANV of this study (corresponding to nt positions 3722-4083 of GenBank Acc. No. HM029238) were translated to deduced aa sequences.
Table 3. Amino acid changes in chicken astrovirus of this study

\begin{tabular}{llcc}
\hline \multicolumn{2}{c}{ Change of amino acid } & Position & $\begin{array}{c}\text { No. of strains showing } \\
\text { the change }\end{array}$ \\
\hline From & \multicolumn{1}{c}{ To } & 256 & $9 / 12$ \\
Lysine & Valine & 257 & $8 / 12$ \\
Alanine & Threonine & 259 & $1 / 12$ \\
Alanine & Proline & 259 & $1 / 12$ \\
Phenylalanine & Valine & 261 & $1 / 12$ \\
Valine & Glycine & 262 & $2 / 12$ \\
Methionine & Arginine & 264 & $1 / 12$ \\
Isoleucine & Valine & 281 & $1 / 12$ \\
Alanine & Arginine & 290 & $1 / 12$ \\
Alanine & Glutamic acid & 296 & $1 / 12$ \\
Alanine & Aspartic acid & 297 & $1 / 12$ \\
Leucine & Glutamic acid & 310 & $3 / 12$ \\
Leucine & Phenylalanine & 315 & $1 / 12$ \\
Isoleucine & Valine & 324 & $1 / 12$ \\
Serine & Phenylalanine & 330 & $3 / 12$ \\
Glycine & Cysteine & 331 & $2 / 12$ \\
Threonine & Proline & 335 & $1 / 12$ \\
\hline Aspartic acid & Glutamic acid & 338 & $1 / 12$ \\
Alanine & Serine & 343 & \\
\hline
\end{tabular}

${ }^{\mathrm{a}}$ Total number of CAstV strains of this study was 12 .

Table 4. Amino acid changes in avian nephritis virus of this study

\begin{tabular}{llcc}
\hline \multicolumn{2}{c}{ Change of amino acid } & Position & $\begin{array}{c}\text { No. of ANV strains } \\
\text { showing the change }\end{array}$ \\
\hline Valine & \multicolumn{1}{c}{ To } & & $1 / 9$ \\
Valine & Glutamic acid & 1256 & $1 / 9$ \\
Valine & Aspartic acid & 1256 & $1 / 9$ \\
Arginine & Tryptophan & 1271 & $8 / 9$ \\
Phenylalanine & Cysteine & 1275 & $1 / 9$ \\
Methionine & Valine & 1287 & $1 / 9$ \\
Threonine & Glycine & 1289 & $1 / 9$ \\
Threonine & Alanine & 1289 & $8 / 9$ \\
Arginine & Proline & 1297 & $1 / 9$ \\
Lysine & Arginine & 1301 & $1 / 9$ \\
Arginine & Lysine & 1302 & $2 / 9$ \\
Isoleucine & Valine & 1318 & $1 / 9$ \\
Valine & Alanine & 1329 & $1 / 9$ \\
Phenylalanine & Serine & 1338 & $1 / 9$ \\
\hline Serine & Leucine & 1339 & $1 / 9$ \\
Valine & Proline & 1342 & $8 / 9$ \\
Phenylalanine & Valine & 1347 & \\
\hline
\end{tabular}

a Total number of ANV strains of this study was 9.

The aa sequences of ANV corresponding to aa positions 1238-1356 of ORF1b of protein ID ADG45752 revealed certain changes as shown in Table 4 . The aa changes from arginine to tryptophan at position 1271 , threonine to alanine at position 


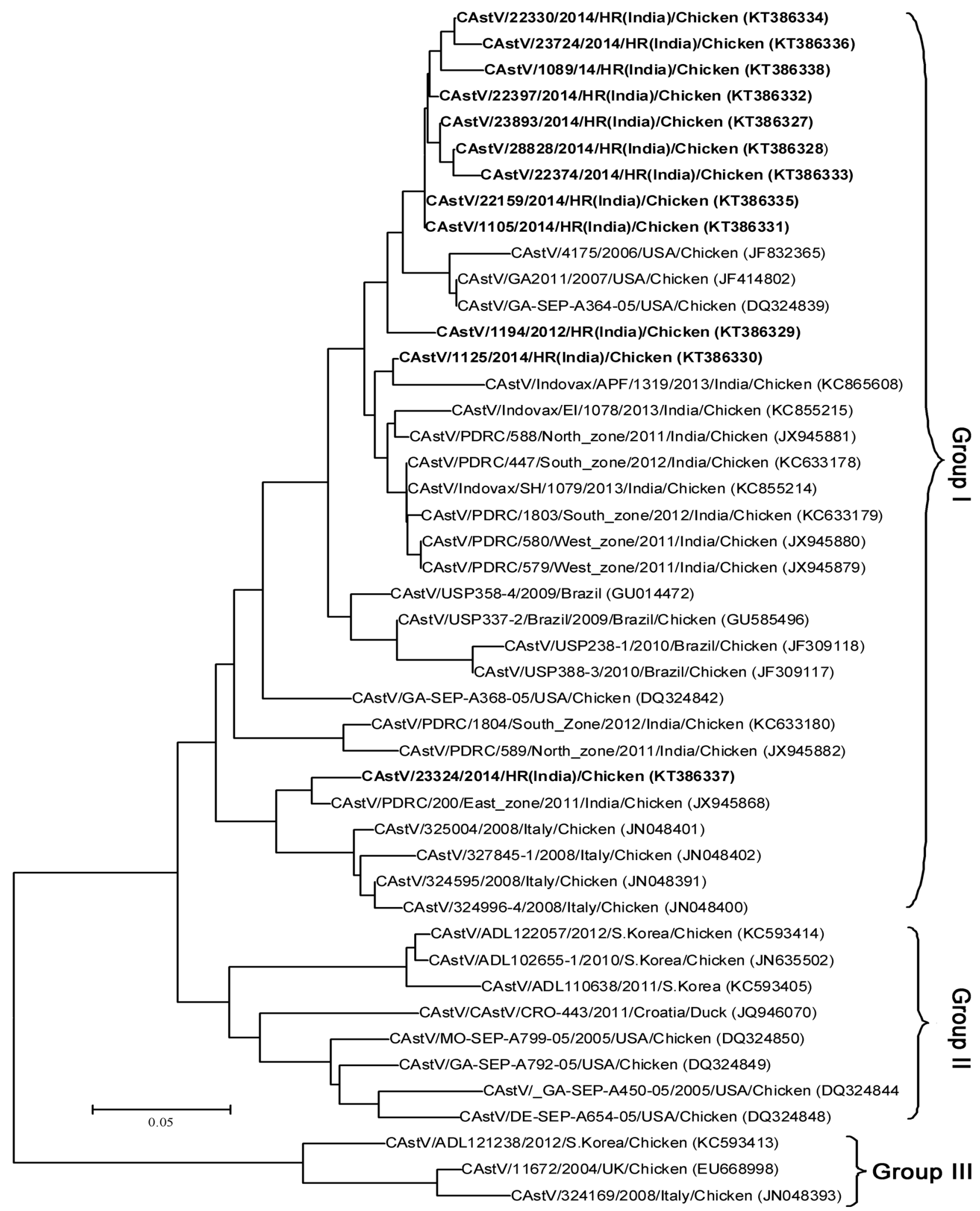

Fig. 1

Phylogenetic tree of the nucleotide sequences (corresponding to nucleotide positions 4170 to 4494 of GenBank Acc. No. JF414802) of polymerase gene of chicken astrovirus

Sequences with GenBank Acc. Nos. are from the present study (in bold) or previously published sequences (in regular). 
1289, arginine to lysine at position 1302 and phenylalanine to valine at position 1347 were observed in 8, 8, 2, and $8 \mathrm{ANV}$ strains of this study in comparison to the reference strain, respectively; however, these changes were also observed in other ANV strains used for comparison. Point mutations at positions 1256, 1275, 1287, 1289, 1297, 1301, 1318, 1329, 1338 and 1339 were observed in ANVs of this study.

\section{Phylogenetic analysis of CAstV and ANV}

For phylogenetic analysis of CAstVs, 11 previously published CAstV's sequences of Indian origin and 23 from abroad were used (Fig. 1). Phylogenetic analysis based on partial polymerase gene nt sequences revealed that all CAstVs clustered in three groups with a majority in group I. All 12 CAstV strains of this study were in group I. The CAstVs (11 of 12 strains) of this study were closer to three previously reported CAstVs from USA and eight previously published Indian strains. The remaining $12^{\text {th }}$ strain of this study (CAstV/23324/2014/HR/India) was closer to a CAstV strain from India (JX945868) and four CAstV strains from Italy. Four American strains, three S. Korean strains and one Croatian strain formed group II while one Italian, U.K. and S. Korean CAstV strains formed group III.

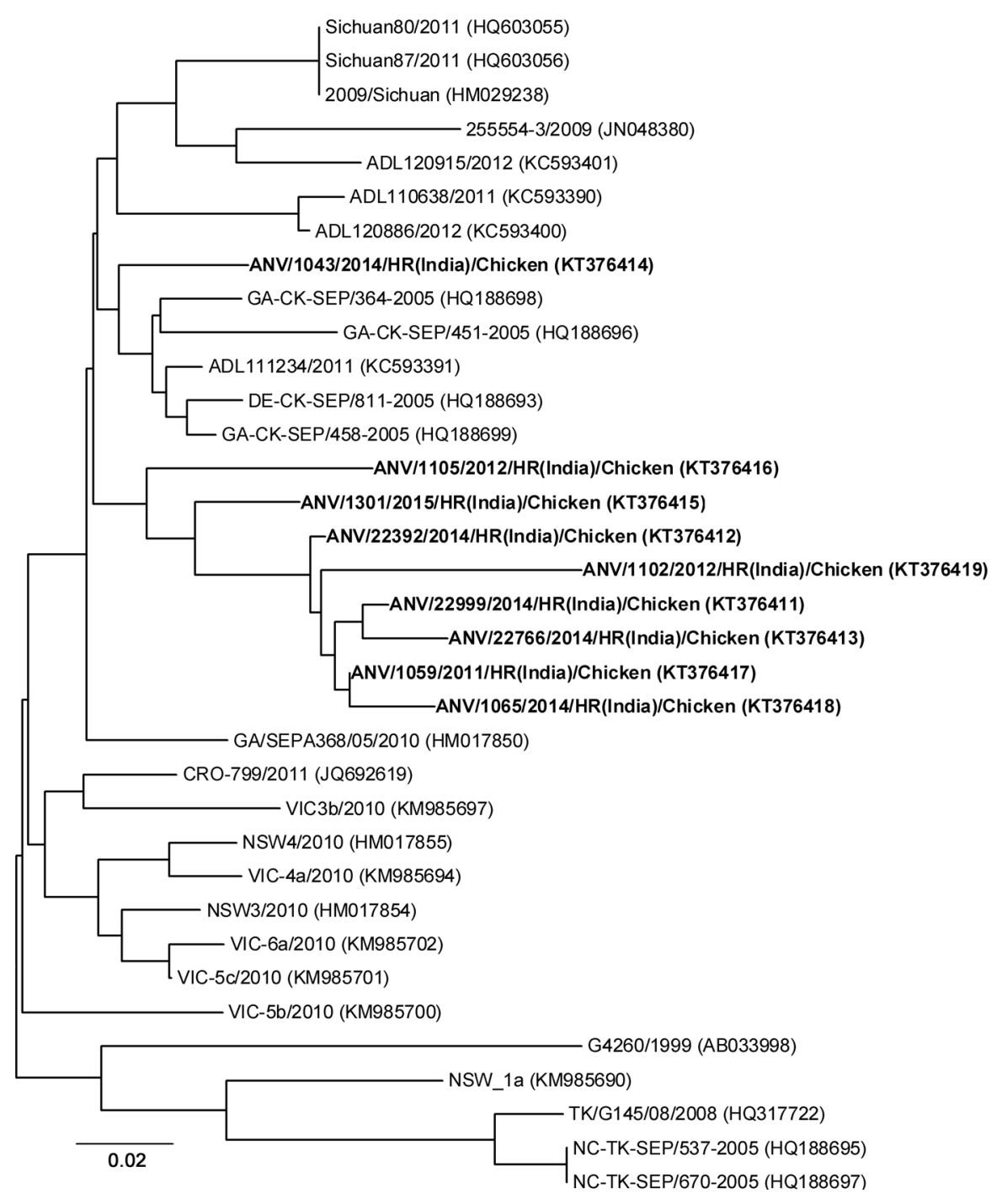

Fig. 2

Phylogenetic tree of the nucleotide sequences (corresponding to nucleotide positions 3722 to 4083 of GenBank Acc. No. HM029238) of polymerase gene of avian nephritis virus

Sequences with GenBank Acc. Nos. are from the present study (in bold) or previously published sequences (in regular). 
For phylogenetic analysis of ANVs, 26 previously published ANV sequences from abroad including one strain of guinea fowl origin and three of turkey origin were used (Fig. 2). Phylogenetic analysis based on partial polymerase gene nt sequences revealed that eight of the nine strains of ANV of this study formed a separate cluster from all other ANV strains used for comparison. The ninth strain (ANV/1043/2014/ HR/India) of this study clustered with an ANV (GA-CK-SEP/364-2005 (HQ188698)) of US origin. The ANVs of turkey origin used for comparison were distantly placed from the ANVs of this study.

\section{Discussion}

The aim of this study was to detect and characterize the presence of three enteric viruses (CAstV, ANV and ARV) in enteritis-affected broiler chickens in India. We did not find any published report on the detection of these three enteric viruses from enteritis cases in India although CAst $\mathrm{V}$ and ANVs have been recently detected and characterized from kidneys of gout-affected broiler chickens (Bulbule et al., 2013). None of the samples in this study were positive for ARV by RT-PCR. It might either be due to very low virus titre that went undetected by RT-PCR or the samples were truly negative for ARV. In one study, Pantin-Jackwood et al. (2007) found commercial turkeys to be negative for ARVs in the US. In a subsequent study, however, these authors (Pantin-Jackwood et al., 2008) reported ARVs in $62.80 \%$ of the chicken flocks and $45.50 \%$ of the turkey flocks tested. Previous studies have reported the presence of ARV in intestinal/faecal samples of broiler chickens (Koo et al., 2013; Mettifogo et al., 2014) although most of these studies indicated low prevalence of ARV as compared to other enteric viruses.

Four flocks were found negative for all three enteric viruses in this study. Pantin-Jackwood et al. (2008) also reported that three of the 43 broiler chicken flocks were negative for enteric viruses (astrovirus, reovirus, rotavirus and coronavirus). There are a number of factors (viruses, bacteria, protozoa, nutritional and management) other than the tested viruses that can cause enteritis. The study revealed high prevalence with $93.80 \%$ samples as positive either for CAstV or ANV or both. Our findings of high prevalence of these two viruses in broiler chickens with diarrhoea are consistent with those of Pantin-Jackwood et al. $(2007,2008)$. The CAstVs or ANVs have previously been detected from chicken flocks (Baxendale and Mebatsion, 2004; Mandoki et al., 2006b; Smyth et al., 2009, 2013; Hewson et al., 2010; De Wit et al., 2011). We did not test these samples for the presence of other viruses and bacteria; their presence in the samples cannot be ruled out. Further studies are required to test these samples for other pathogens.
Both CAstV and ANV have been reported to cause stunted growth and/or diarrhoea in chickens. Baxendale and Mebatsion (2004) isolated CAstV from diarrhoeic broiler chicks and inoculated this virus to 1 day old SPF White Leghorn chicks. The inoculated chicks developed diarrhoea and distension of small intestine and none of the uninoculated chicks showed signs of diarrhoea. De Wit et al. (2011) inoculated 3-week-old SPF layer chickens with an ANV (isolate 19), which resulted in diarrhoea and severe depression and mortality and pathological changes in kidneys and lymphoid organs. Kang et al. (2012) exposed 1 day old commercial broilers to litter contaminated by chickens with RSS and reported a 70\% decrease in weight in the RSSexposed group compared with the unexposed controls. The nucleic acid specific for CAstV and ANV-1 and ANV-2 were detected in RSS exposed birds indicating that astroviruses probably play an important role during RSS. These studies indicate that both the viruses have potential to cause enteritis in chickens on their own.

Both CAstV and ANV together were found in $40.00 \%$ of cases. Detection of two or more than two enteric viruses from enteritis cases in chickens has been reported earlier (Pantin-Jackwood et al., 2008; Smyth et al., 2009; Roussan et al., 2012; Koo et al., 2013; Mettifogo et al., 2014). Two or more enteric viruses have also been reported in turkeys by Jindal et al. (2010) and Moura-Alverez et al. (2013). It is possible that these viruses in combination may cause additive or synergistic adverse effects in birds. As mentioned earlier, both viruses (CAstV and ANV) individually can cause diarrhoea, depression, decreased weight gain and mortality. Growth depression due to diarrhoea may lead to considerable economic losses to the poultry farmers as the affected birds may not attain desired weight at marketing. In a study, Barnes et al. (2000) reported that estimated losses to the US turkey industry from growth depression due to poult enteritis complex would be between US $\$ 300$ and US\$400 million annually if 10-15\% growth depression would occur throughout the turkey industry in the US. In an experimental study, Jindal et al. (2009) orally inoculated PES material in 14-day old turkey poults to produce PES and found $31.80 \%$ decrease in body weight in inoculated poults as compared to controls. Such a decrease in body weight would certainly lower the profit margins of poultry growers. Such a situation as observed in turkeys with regards to decreased body weights can also be expected in broiler chickens and experimental studies are needed on this aspect.

Analysis of nt and aa sequences of CAstV of this study revealed varied identity with previously reported strains from India and abroad. The conservation plot based analysis revealed unique and consensus aa changes in CAstV strains of this study from earlier reported strains used for comparison. All CAstVs of this study clustered in a group in polymerase gene phylogeny. However, Smyth et al. (2009) 
reported the existence of two groups of CAstVs based on partial ORF1b phylogeny. Based on polymerase and capsid gene phylogeny of 23 isolates of TAstVs, Pantin-Jackwood et al. (2006) reported high level of genetic variations among the astrovirus isolates suggesting the possibility of circulation of more than one serotype of the virus. Bulbule et al. (2013) reported two groups of CAstVs from gout cases and designated them as Indian group 1 and Indian group 2 based on phylogenetic analysis of the polymerase aa sequences. Genetic variations in polymerase gene have been reported due to positive selection because of synonymous to nonsynonymous nucleotide substitution ratio (Pantin-Jackwood et al., 2006). Positive molecular selection was also observed for the polymerase gene of other viruses including avian influenza virus (Campitelli et al., 2006). In the present study, we amplified a part of polymerase gene; determination of the complete genome therefore needs to be considered for genotyping of CAstVs. Though the present study was conducted in a specific region, screening of suspected enteritis cases in large geographical region may help uncover other types of CAstVs circulating in poultry.

Our observations of varying levels of nt and aa identities of ANV compared with previously published polymerase gene sequences of ANV from abroad are consistent with the earlier reports (Canelli et al., 2012; Kang et al., 2012). Phylogenetic analysis revealed that all ANVs of this study clustered together. Mandoki et al. (2006a) reported that nt sequences of Hungarian ANVs showed 76 to $86 \%$ identity with the reference strain from Japan and had high diversity regardless of their origin and year of sampling. Similarly, Todd et al. (2011) reported high level of capsid gene diversity and co-circulation of diverse ANVs based on capsid gene sequence analysis of 25 ANVs from UK, Germany and Belgium. ANVs differ antigenically and at least two different serotypes (ANV-1 and ANV-2) have been detected on the basis of indirect immunofluorescence and virus neutralization tests (Shirai et al., 1991). ANV isolates may also vary with regard to pathogenicity and tropism. For example, the G-4260 isolate (ANV-1) differed from the M8 (ANV-2) and WG5 (ANV-3) isolates in terms of causing growth retardation and kidney lesions (Shirai et al., 1991, 1992). It remains to be seen as to which serotype(s) the ANVs of our study belong.

The present study revealed the presence of CAstV and ANV either alone or in combination in enteritis-affected broiler chickens in India. This appears to be first report indicating the presence of both of these viruses in enteritisaffected birds in India. The changes at the nucleotide/amino acid level both in CAstV and ANV warrant further studies for better understanding of their epidemiology. Further studies are also needed to determine the changes in highly variable capsid gene of both viruses which will help to understand the virus epidemiology regarding the types of viral strains circulating in enteritis-affected broiler chickens and correlation of their virulence and antigenicity with the prevailing changes at genetic level.

The impact of aa changes in polymerase gene on antigenicity and virulence of the CAstVs needs to be explored. Also, the impact of these viruses on broiler performance needs to be thoroughly investigated. Although virally induced enteric diseases are economic burden on poultry growers, no single virus has emerged as a likely causative agent so that appropriate prevention and control efforts could be applied (Day et al., 2010). Complete understanding of the contribution of enteric viruses and other pathogens in enteric diseases of chicken still have a long way to go in the development of preventive and control measures.

\section{References}

Barnes HJ, Guy JS, Vaillancourt JP (2000): Poult enteritis complex. Rev. Sci. Tech. 19, 565-588. https:/doi.org/10.20506/ rst.19.2.1234

Baxendale W, Mebatsion T (2004): The isolation and characterization of astroviruses from chickens. Avian Pathol. 33, 364-370. https:/doi.org/10.1080/0307945042000220426

Bulbule NR, Mandakhalikar KD, Kapgate SS, DeshmukhVV, Schat KA, Chawak MM (2013): Role of chicken astrovirus as a causative agent of gout in commercial broilers in India. Avian Pathol. 42, 464-473. https:/doi.org/10.1080/0307 $\underline{9457.2013 .828194}$

Campitelli L, Ciccozzi M, Salemi M, Taglia F, Boros S, Donatelli I, Rezza G (2006): H5N1 influenza virus evolution: a comparison of different epidemics in birds and humans (1997-2004). J. Gen. Virol. 87, 955-960. https:/doi. org/10.1099/vir.0.81397-0

Canelli E, Cordioli P, Barbieri I, Catella A, Pennelli D, Ceruti R, Moreno A, Lavazza A (2012): Astroviruses as causative agents of poultry enteritis: genetic characterization and longitudinal studies on field conditions. Avian Dis. 56, 173-182. https:/doi.org/10.1637/9831-061311-Reg.1

Connor TJ, McNeilly F, McFerran JB, McNulty MS (1987): A survey of avian sera from Northern Ireland for antibody to avian nephritis virus. Avian Pathol. 16, 15-20. https:/doi. org/10.1080/03079458708436348

Davis JF, Kulkarni A, Fletcher O (2013): Reovirus infection in young broiler chickens. Avian Dis. 57, 321-325. https:/ doi.org/10.1637/10515-021313-Case.1

Day JM, Ballard LL, Duke MV, Scheffler BE, Zsak L (2010): Metagenomic analysis of the turkey gut RNA virus community. Virol. J. 7, 313. https:/doi.org/10.1186/1743$\underline{422 x-7-313}$

Day JM, Spackman E, Pantin-Jackwood MJ (2007): A multiplex RT-PCR test for the differential identification of turkey astrovirus type 1, turkey astrovirus type 2, chicken astrovirus, avian nephritis virus, and avian rotavirus. Avian Dis. 51, 681-684. https:/doi.org/10.1637/0005-2086(2007)51[681:AMRTFT]2.0.CO;2 
Day JM, Zsak L (2013): Recent progress in the characterization of avian enteric viruses. Avian Dis. 57, 573-580. https:/doi. org/10.1637/10390-092712-Review.1

De Wit JJ, Dam GB, de Laar JM, Biermann Y, Verstegen I, Edens F, Schrier CC (2011): Detection and characterization of a new astrovirus in chicken and turkeys with enteric and locomotion disorders. Avian Pathol. 40, 453-461. https:/ doi.org/10.1080/03079457.2011.596813

Hewson KA, O'Rourke D, Noormohammadi, AH (2010): Detection of avian nephritis virus in Australian chicken flocks. Avian Dis. 54, 990-993. https:/doi.org/10.1637/9230010610-Reg.1

Imada T, Yamaguchi S, Mase M, Tsukamoto K, Kubo M, Morooka A (2000): Avian nephritis virus (ANV) as a new member of the family Astroviridae and construction of infectious ANV cDNA. J. Virol. 74, 8487-8493. https:/doi. org/10.1128/JVI.74.18.8487-8493.2000

Imada T, Yamaguchi S, Miura N, Kawamura H (1980): Antibody survey against avian nephritis virus among chickens in Japan. Nat. Inst. Anim. Hlth. Q (Tokyo) 20, 79-80.

Jindal N, Chander Y, Patnayak DP, Mor SK, Ziegler AF, Goyal SM (2012): A multiplex RT-PCR for the detection of astrovirus, rotavirus, and reovirus in turkeys. Avian Dis. 56, 592-596. https:/doi.org/10.1637/9958-100911ResNote.1

Jindal N, Patnayak DP, Chander Y, Ziegler AF, Goyal SM (2010): Detection and molecular characterization of enteric viruses from poult enteritis syndrome in turkeys. Poult. Sci. 89, 217-226. https:/doi.org/10.3382/ps.2009$\underline{00424}$

Jindal N, Patnayak DP, Ziegler AF, Lago A, Goyal SM (2009): Experimental reproduction of poult enteritis syndrome: clinical findings, growth response and microbiology. Poult. Sci. 88, 949-958. https:/doi.org/10.3382/ps.2008-00490

Kang KI, El-Gazzar M, Sellers HS, Dorea F, Williams SM, Kim T, Collett S, Mundt E (2012): Investigation into the aetiology of runting and stunting syndrome in chickens. Avian Pathol. 41, 41-50. https:/doi.org/10.1080/03079457.201 1.632402

KociMDSchultz-CherryS(2002): Avian astroviruses. Avian Pathol.31, 213-227. https:/doi.org/10.1080/03079450220136521

Koo BS, Lee HR, Jeon EO, Han MS, Min KC, Lee SB, Mo IP (2013): Molecular survey of enteric viruses in commercial chicken farms in Korea with a history of enteritis. Poult. Sci. 92, 2876-2885. https:/doi.org/10.3382/ps.2013-03280

Mandoki M, Bakonyi T, Ivanics E, Nemes C, Dobos-Kovacs M, Rusvai M (2006a): Phylogenetic diversity of avian nephritis virus in Hungarian chicken flocks. Avian Pathol. 35, 224-229. https:/doi.org/10.1080/03079450600711037

Mandoki M, Dobos-Kovacs M, Bakonyi T, Rusvai M (2006b): Molecular diagnosis of avian nephritis: preliminary report. Acta Veterinaria Hungarica, 54, 51-60. https:/doi. org/10.1556/AVet.54.2006.1.6

Matsui SM, Greenberg HB (2001): Astroviruses. In Fields B, Knipe D, Howley P (Eds): Fields Virology. 4th edn. LippincottRaven, Philadelphia, pp. 875-893.

Mettifogo E, Nunez LF, Chacon JL, Santander Parra SH, AstolfiFerreira CS, Jerez JA, Jones RC, Piantino Ferreira AJ
(2014): Emergence of enteric viruses in production chickens is a concern for avian health. Sci. World J. https:/ doi.org/10.1155/2014/450423

Moura-Alvarez J, Chacon JV, Scanavini LS, Nunez LF, AstolfiFerreira CS, Jones RC, Piantino Ferreira AJ (2013): Enteric viruses in Brazilian turkey flocks: Single and multiple virus infection frequency according to age and clinical signs of intestinal disease. Poult. Sci. 92, 945-955. https:/ doi.org/10.3382/ps.2012-02849

Pantin-Jackwood MJ, Day JM, Jackwood MW, Spackman E (2008): Enteric viruses detected by molecular methods in commercial chicken and turkey flocks in the United States between 2005 and 2006. Avian Dis. 52, 235-244. https:/ doi.org/10.1637/8174-111507-Reg.1

Pantin-Jackwood MJ, Spackman E, Day JM, Rives D (2007): Periodic monitoring of commercial turkeys for enteric viruses indicates continuous presence of astrovirus and rotavirus on the farms. Avian Dis. 51, 674-680. https:/doi.org/10.1637/0005-2086(2007)51[674:PMOCTF]2.0.CO;2

Pantin-Jackwood MJ, Spackman E, Woolcock PR (2006): Molecular characterization and typing of chicken and turkey astroviruses circulating in the United States: implications for diagnostics. Avian Dis. 50, 397-404. https:/doi. org/10.1637/7512-020606R.1

Pantin-Jackwood MJ, Strother KO, Mundt E, Zsak L, Day JM, Spackman E (2011): Molecular characterization of avian astroviruses. Arch. Virol. 156, 235-244. https:/doi. org/10.1007/s00705-010-0849-Z

Rosenberger JK (2003): Reovirus infections. In Saif YM, Barnes HJ, Glisson JR, Fadly AM, McDougald LR, Swayne DE (Eds). Diseases of Poultry. 11th edn. Blackwell Publishers, Ames, Iowa, USA, pp. 283-298.

Roussan DA, Shaheen IA, Khawaldeh GY, Totanji WS, Al-Rifai RH (2012): Simultaneous detection of astrovirus, rotavirus, reovirus and adenovirus type I in broiler chicken flocks. Polish J. Vet. Sci. 15, 337-344. https:/doi.org/10.2478/ v10181-012-0052-0

Saif YM (2003): Viral enteric infections. In Saif YM, Barnes HJ, Glisson JR, Fadly AM, McDougald LR, Swayne DE (Eds). Diseases of Poultry. 11th edn. Blackwell Publishers, Ames, Iowa, USA, pp. 299-300.

Sajewicz-Krukowska J, Pac K, Lisowska A, Pikula A, Minta Z, Kroliczewska B, Domanska-Blicharz K (2016): Astrovirus induced 'white chicks' condition-field observation, virus detection and preliminary characterization. Avian Pathol. 45, 2-12. https:/doi.org/10.1080/03079457.2015 $\underline{.1114173}$

Shirai J, Nakamura K, Shinohara K, Kawamura H (1991): Pathogenicity and antigenicity of avian nephritis isolates. Avian Dis. 35, 49-54. https:/doi.org/10.2307/1591294

Shirai J, Tanimura N, Uramoto K, Narita M, Nakamura K, Kawamura H (1992): Pathologically and serologically different avian nephritis virus isolates implicated in etiology of baby chick nephropathy. Avian Dis. 36, 369-377. https:/ doi.org/10.2307/1591515

Smyth VJ, Jewhurst HL, Adair BM, Todd D (2009): Detection of chicken astrovirus by reverse transcriptase-polymerase 
chain reaction. Avian Pathol. 38, 293-299. https:/doi. org/10.1080/03079450903055397

Smyth V, Trudgett J, Wylie M, Jewhurst H, Conway B, Welsh M, Kaukonen E, Perko-Makela P (2013): Chicken astrovirus detected in hatchability problems associated with 'white chicks'. Vet. Rec. 173, 403-404. https:/doi.org/10.1136/ vr.f6393

Tamura K, Stecher G, Peterson D, Filipski A, Kumar S (2013): MEGA6: Molecular evolutionary genetics analysis version 6.0. Mol. Biol. Evol. 30, 2725-2729. https:/doi. org $/ 10.1093 / \mathrm{molbev} / \mathrm{mst} 197$

Todd D, Trudgett JS, Smyth VJ, Donnelly B, McBride N, Welsh MD (2011): Capsid protein sequence diversity of avian nephritis virus. Avian Pathol. 40, 249-259. https:/doi.or $\mathrm{g} / 10.1080 / 03079457.2011 .553583$

Yamaguchi S, Imada T, Kawamura H (1979): Characterization of a picornavirus isolated from broiler chicks. Avian Dis. 23, 571-581. https:/doi.org/10.2307/1589732 